\title{
Occlusion and posture: facts and beliefs
}

\author{
Philippe AMAT
}

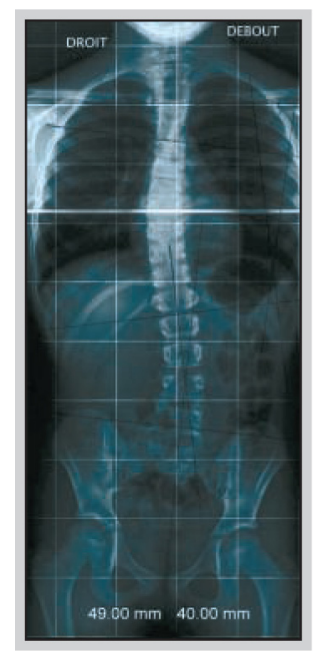

if you close the door against all errors, truth will be locked out, too.

Rabindranàth TAGORE

Sâdhanâ

Address for correspondence:

P. AMAT,

19 place des Comtes

du Maine,

72000 Le Mans.

amatph@noos.fr

\section{ABSTRACT}

The relationship between occlusion and posture has been a continual source of interest to all participants in the delivery of health care. But a certain amount of confusion still beclouds the subject because of the wide diversity of therapeutic approaches designed to deal with it and the weakness of methodological design in the scientific studies that have been published on it to date.

This article addresses the questions raised by that correlation between occlusion and posture as well as the therapeutic implications of a clinical approach integrating treatment of corporal posture into orthodontic care. A review of the literature shows that there is a dearth of reliable experimental data dealing with this subject. The data that is available points to the existence of this correlation and also asserts the prevalence of associations between idiopathic scoliosis and cranio-facial anomalies in adolescents.

The published facts appear to support our clinical impressions and subjective convictions. In order to enlarge our vision to encompass patients as entire human beings instead of compartmentalized biological segments each to be treated by an appropriate specialty it would be helpful if members of the various medical disciplines improved the

\section{6}


lines of communication with each other. An equally desirable development would be the establishment of fundamental research and clinical programs that would help to establish causal relationships that would put therapy on evidence based foundation.

\section{KEYWORDS}

Evidence-based medicine

Posture

Dental occlusion

Scoliosis

Malocclusion

Dento-facial orthopedics.

\section{1 - INTRODUCTION}

In dento-facial orthopedics, and in a more general way in all of dentistry, we live in an era in which postural considerations are being integrated into our therapy.

It is probably fair to say that the inter-relationship between occlusion and posture have long interested a significant number of practitioners. However, a certain amount of confusion surrounds this connection because of the great variety of therapeutic approaches proposed for dealing with it as well as the lack of methodological rigor employed for most of the published studies devoted to it.
The inter-actions between posture and occlusion constitute a vast subject, one that cannot be treated adequately in a single article. With this presentation we hope to stimulate discussion and thinking about it and suggest that scientific study can often corroborate our original unsubstantiated convictions. Clearly for orthodontists taking posture into account in their diagnoses and therapies should not be considered a major paradigm shift in the way they practice their profession but a simple extension of their efforts to provide their patients with the best possible all-inclusive therapy.

\section{2 - OCCLUSION AND POSTURE: A RECIPROCAL INTER-CHANGE}

\section{2 - 1 - Definitions}

Le Littré defines occlusion as "closing," the temporary coming together of an entity that opens naturally.
Our subject is dental occlusion. The dictionary of orthognathics ${ }^{23}$ published by the Société Frangaise d'Orthopédie Dento-Faciale defines it as a phrase in current use employed 
to described the reciprocal action of the dental arches.

The same tome offers a double definition of posture:

- the habitual stance of the body or parts of it supported by the action and constraints of tonic muscles that work to fix the body segments through joints designed to maintain equilibrium;

- bodily stance derived from the interaction of bodily weight and the sensori-motor complex (derived from the labyrinth of the inner ear, the Pacini bodies, the Golgi apparatus, the joints, the plantar surfaces of the feet (fig. 1).

\section{2 - 2 - Posture and dento- facial orthopedics}

Health care professionals and Citizens at large today take a serious interest in posture. The general press frequently publishes articles about the relationship between dental occlusion and bodily posture, particularly as it interacts with athletic activities. Many professional journals also include this topic in their purview and the dental literature has been enriched with many works dealing with the topic of posture in odontology. Scientific societies like the National College of Odontology, which has devoted three of its annual conventions

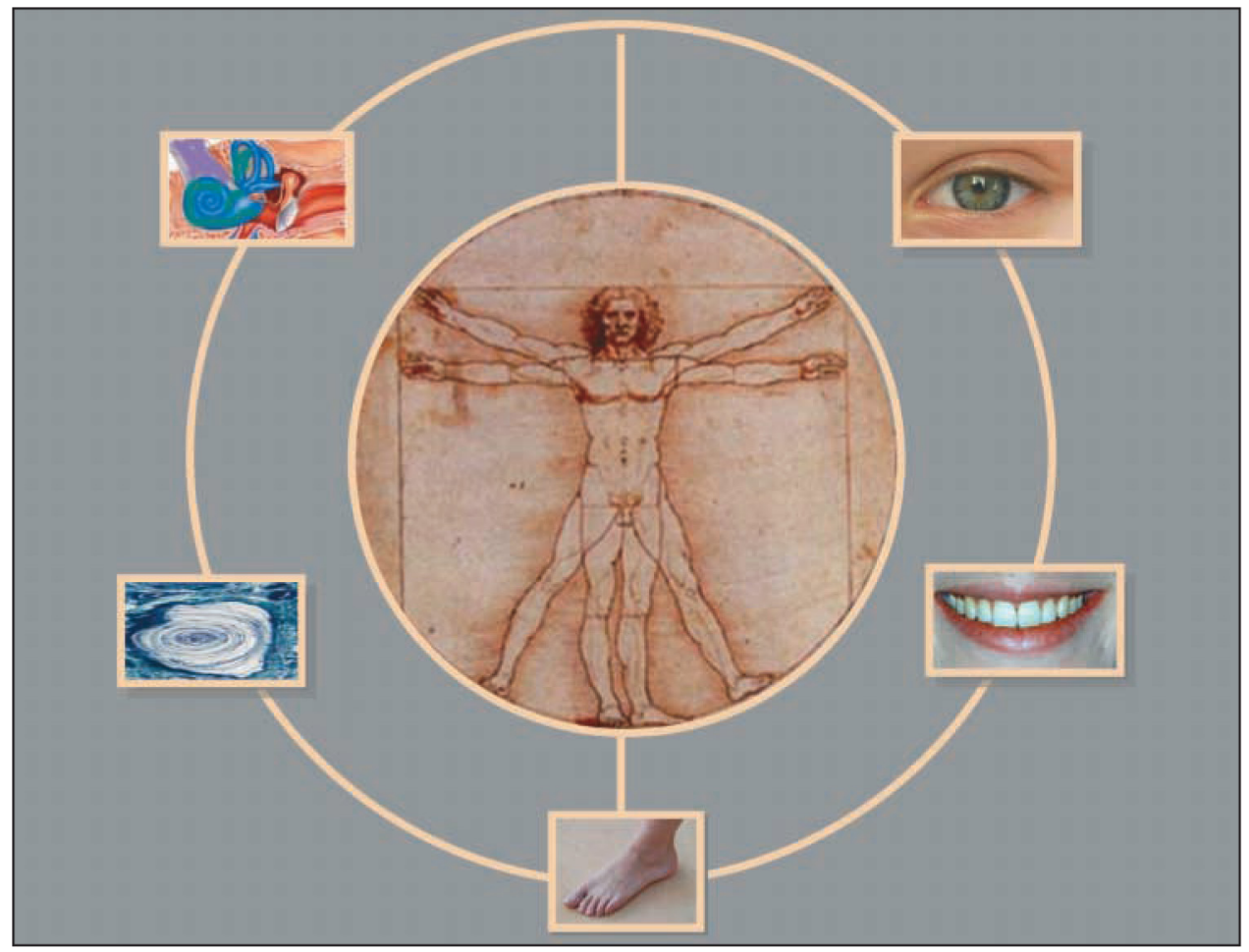

Figure 1

The global man. 
to it, regularly address the topic. And practitioners receive numerous invitations to take courses on the subject.

In this sense, dento-facial orthopedics is also affected by posture. Orthodontic treatment is aimed at correcting dento-facial structures usually at a time when growth is highly active so that part of its role is to supervise this growth and to assist it when indicated as the process of correcting anomalies proceeds. The objectives of orthodontic treatment are to optimize the ensemble of orofacial functioning and to ameliorate the equilibrium of teeth in the arches, in relation to skeletal structures, to the periodontium, to the joints, to bodily posture, and to the biopsychosocial comportment of the patient ${ }^{10}$.

Orthodontists should take a consistent and on-going interest in the posture of their patients. In addition to the establishment of the dental objectives of their mechano-therapy they should also be attentive to the eventual relationship between occlusion and cephalic as well as over-all bodily posture, taking into account physiological regulation of varying mandibulo-cranial positions. It is equally important that they consider the interaction between cranio-cervical posture and craniofacial morphogenesis 88,90 . Finally, and, perhaps, most important, they give breathing a central position in their therapeutic objectives ${ }^{95}$. As specialists in a sector of child development, orthodontists should seek to detect, to prevent, and when necessary, to provide early treatment for any type of persistent nasal obstruction, before that problem can have a harmful impact on dento-facial morphology. In this role they should devote their atten- tion to the interrelation between breathing problems and posture, and, especially, in the cranio-cervical region, to postural adaptations capable of preventing the collapse of the airways of the pharyn $x^{96}$.

Although a wide consensus of patients and professionals from a variety of disciplines agrees that a relationship between dental occlusion and posture exists, a clear statement of what the proper modalities for dealing with posture as an orthodontic objective has not yet been formulated.

\section{2 - 3 - Therapeutic implications}

Clinically, orthodontists have to confront and attempt to answer numerous questions. In the first place, they find that interest bearing on the relationship between occlusion and posture leads them into a battleground with at least two fronts. Patients consult them seeking occlusal treatment that they hope, or have been told by practitioners in allied fields, will help to improve their postural problems. How should we respond to these requests? Our patients have a right not to be deprived of effective treatment, no matter what it might be. They also have the right to benefit from true informed consent and we have the obligation to tell them exactly what medical benefit they can expect to derive from therapy, especially if that therapy is invasive. In other words, they have a right to be presented with a clear cost/benefit/ risk analysis.

Moreover, dento-facial orthopedics should be concerned with whole patients, not just their masticatory apparatuses, with their posture as 
well as with their occlusion. But we should know what effect our treatments actually have on posture. And to answer these preoccupations we must differentiate our clinical hypotheses from documented studies, in other words we must recognize that our convictions are not necessarily equivalent to proven facts. Ultimately, we must base our treatments on evidence based orthodontics not speculation. And we should remember that the "postural dimension" often relies heavily on holistic medical concepts like energetics, applied chiropractic, osteopathy, and Chinese medicine, none of which are noted for their adherence to the evidence based approach. As clinicians, we have to weigh carefully how much we should satisfy those of our patients who desire to receive treatment that is not evidence based.

It would also seem that there exists a link between the correction of postural problems and the patient's cognitive and emotional status ${ }^{47}$. It would also seem to be desirable if orthodontists included postural status in the establishment of a diagnosis and of a treatment plan. Finally, the notion of taking charge of the whole patient has to fight the road blocks of the segmentation of medical knowledge into individual specialties. In order to follow the advice of René Dubos and "think globally, act locally" it is an indispensable requirement for us to work in close collaboration with other health care specialties and to adopt an open minded, pragmatic, but always rigorously scientific point of view.

\section{3 - OCCLUSION AND POSTURE: FACTS AND BELIEFS}

\section{3 - 1 - Can we deliver appropriate health care with only our beliefs as a basis for our treatment philosophy?}

It would seem to perfectly natural for us to base our therapeutic decisions upon our convictions, our personal clinical experience or upon clinical cases that we have read about or seen. Nevertheless, we have easy access to the literature that makes available to us the considerable professional experience of thousands of practitioners treating millions of patients. Why should we deprive our patients of the benefits we can derive from using that literature?

Still, if a therapy seems effective in our hands, wouldn't it be fruitless to do a research study to find published facts that simply substantiate what we already know works? Well, no. Such a research study would be useful because it might turn out that we have deceived ourselves because we haven't realized that no matter how much conviction, intellectual honesty and rigor clinicians may devote to their practices, experience and belief are not a sound enough basis for the formulation of the best possible treatment plans ${ }^{9}$.

Research projects evaluating treatment results have demonstrated that patients being treated in evidence based procedures do better than whose treatment is not evidence based $^{40,51}$.

Of course the effects of inadequate treatment are less grave in orthodontics than they are in cardiology ${ }^{40}$. 
That doesn't mean the possibly hidden unfortunate outcomes in our specialty are not troubling and should$n$ 't be vigilantly guarded against. For example, in our specialty the extraction of four molars has been for many years prescribed, without proven success, to deal with an excess of vertical dimension. If we hadn't let ourselves be deceived by an alluring and tempting trap ${ }^{15}$, if we had only based our therapeutic decisions a little more solidly on evidence, on proven principals of biomechanics and neuro-muscular physiology, many of these useless extractions might have been avoided.

\section{3 - 2 - The indispensable evidence-based approach}

Designed to help us achieve a global improvement in the quality of our treatment and to bridge the gap between clinical research and the health care we deliver, the evidencebased approach has been widely accepted in the medical community. It is a procedure that helps clinicians to make decisions. It asks us to base our clinical choices, as we always have, on our knowledge of theory, on our judgment, and on our experience, which are the principal components of decision making in traditional practice. But it also asks us to take into account the most relevant data available in the published medical literature as well as to carefully consider the preferences of our patients ${ }^{56,79}$.

Clearly this evidence-based approach complements the practice of medicine in the traditional way but it does not replace it: neither the most convinc- ing results of clinical research nor individual clinical competence guarantee, in themselves, a high quality practice. Without the support of the best available published data our practices risk becoming rapidly out of date. But, of course, it is also true that without clinical competence no amount of published data, whether or not it is relevant, can be of any help in the delivery of adequate care to our patients.

Evidence-based dento-facial orthopedics $^{8}$ describes the application of factual data to our specialty. Let us emphasize that its three components, clinical experience, the best available published data on clinical research, and the values and preferences of our patients, must be welded together so that orthodontists and their patients can cooperate fully in a diagnostic and therapeutic alliance (fig. 2). The most thorough going review of the literature devoted to the postural approach will, unfortunately, uncover a miniscule number of controlled studies carried out with methodological rigor. This, of course, is not a problem that is limited to posturology. In orthodontics, as in the ensemble of medicine ${ }^{80}$, only a limited number of the procedures we carry out can be said to be incontestably evidence-based. So wouldn't an attempt to revamp our practices to conform to the dictates of the evidence-based philosophy be a great waste of time? Shouldn't we wait until a greater amount of data is published? Absolutely not! Practitioners can certainly maintain a rigorous scientific attitude even if the number of published studies is slim and the available data is weak ${ }^{43}$. When the evidence is feeble we, in concert with our patients and their families, must nevertheless deal with our doubts and make the best decisions we can 


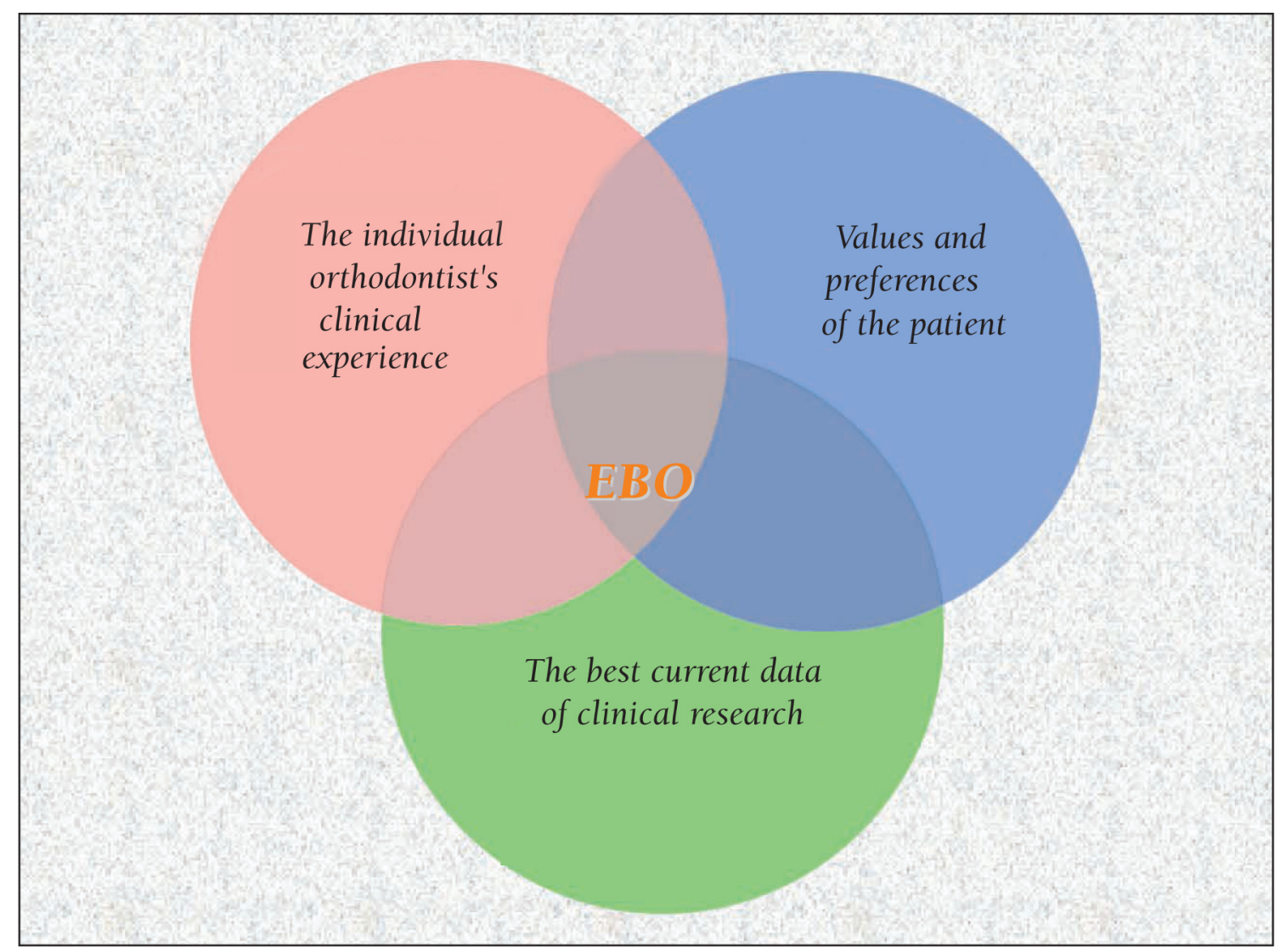

Figure 2

Evidence based orthodontic's diagnosis and therapeutic alliance ${ }^{8}$.

on the basis of the proven data that we do have, no matter how slim. Using the established evidence-based approach we can make our diagnoses more effectively and more quickly with the data at hand.

Remember, the evidence-based method doesn't limit our therapeutic choices proposed for a given patient to the techniques we have habitually employed. It is also true that the success of any given treatment doesn't mean it was accomplished with the therapy best suited to the situation nor that it offered to the patient all of the known medical health care aid that could have helped in dealing with the problem ${ }^{9}$. The evidence-based approach should remain and be recognized for what it is, a simple aid to clinical decisions. We should not misuse its essence by transforming it into a strait jacket that could reduce the variety and extent of our clinical practice or suffocate our indispensable search for newer and better treatment methods. It would be especially regrettable if the fact that no psychopathological mechanism for the relationship between occlusion and posture has as yet been scientifically elucidated made us deny the possibility that it exists. After all apples didn't wait for Newton to demonstrate the 
laws of gravity before they began to fall off trees.

\section{3 - 3 - Occlusion and posture: what does appear in the literature}

\section{3 - 3 - 1 - The questions}

In addition to the simple issue of the existence of a relationship between occlusion and posture, several other questions have been posed.

What are the criteria for normal posture of the body, the head and the spinal column, and the mandibulo-cranial complex? Are these criteria valid? How should malfunctions of posture be defined? What are the consequences of the malfunctions structurally, in causing pain, and can they be evaluated in terms of deficiency, of incapacity, or of handicap ${ }^{4}$ ? And have the results of postural treatment been confirmed by controlled studies?

Clinicians should also ask themselves about the nature of the mechanisms of the regulation of posture and the limits of postural adaptation. Is orthodontic treatment a contributing factor to the etiology of postural deformities or isn't it? Can changes in occlusion affect, in a clinically significant manner, global postural equilibrium? Can occlusion actually provoke postural disturbances or pathological ailments in sites far distant from the oral cavity?

Variations in dental occlusion are manifold and appear in a variety of ways; malformations, attrition due to function or faulty habits, irregularities of teeth, and changes resulting from dental restorations, orthodontic care, and prosthetic rehabilitation. What eventual influence does each of these have on postural balance?

Paul Pionchon and Gérard Duminil ${ }^{72}$ have reviewed this multiplicity of questions aroused by the relationship between occlusion and posture. They also asked themselves about the concept of holistic treatment of the "whole patient," and continued with an interrogation of what that might mean. "Is it a system of bones and joints, a system of muscles and their innervations, a system with interactions of the peripheral and central nervous system with their sensory and motor components, or is it a psychic emotional and cognitive apparatus inserted in system reflecting socio-cultural factors?"

Finally, another interrogation is based on the possible role that dentofacial orthopedic therapy could have in the treatment of postural disorders.

\section{3 - 3 - 2 - The weakness of published data}

Most publications devoted to the connections between posture and occlusion have been prepared with meager methodological rigor which makes it difficult to derive a clear answer from them to the questions that we have just outlined.

It is important to bear in mind that a hierarchy of data ${ }^{37,78}$ is available for evaluating the relative value of published studies as a function of the protocol for the research methods employed. This classification does not prejudge the intrinsic qualities of the studies themselves, that is, their strong points and their weak ones. Their quality is evaluated with the aid of a series of questions proposed by the evidencebased medicine group at McMaster University ${ }^{80}$. Systematic reviews ${ }^{7,94}$ and 
randomized and controlled trials are the types of reports the least likely to be affected by bias. Bias, it should be remembered, can appear in a study when factors other than those being studied, such as life style or genetics, can influence the results.

In any assessment it is quite clear that a great many of the articles dealing with the relationship between occlusion and posture are anecdotal reports of clinical cases that have little status as scientific evidence. While publication of these types of cases is useful for attracting the attention of clinicians to a precise point or for proposing useful future avenues of research, they are not a useful basis for basing the systemic preparation of a therapeutic approach.

The scientific studies that have been devoted to the relationship of occlusion to posture suffer, as a group, from a variety of flaws. We can site the non-random separation of patients into groups to be studied, the failure, at the close of the study, to measure all of the patients that had participated in the trial, or, to put it in another way, the omission of some of the participants. We should add the frequent defect of poor definition of the criteria for inclusion or exclusion of subjects, the use of patient samples too small in size, and the failure to carefully define the validity of the tests employed with regard to their sensitivity, specificity, and reproduceability.

This is not a new criticism. As far back 2000, Olivier Laplanche et al. ${ }^{52}$ brought our attention to this point in their review of the literature.

In 2007, another systematic review of the literature ${ }^{41}$ focused attention on the low level of scientific methodological rigor in published studies: only
$0.8 \%$ of them attained level II of randomized controlled studies, $17.7 \%$ of them could be included in level III of controlled but not randomized with study groups and control groups, $50.1 \%$ were judged to be level IV consisting of transverse studies that were a series of clinical cases, and $31.3 \%$ were deemed to be level $V$, which were non-systematic reviews and opinions of so-called experts.

\section{3- 3- 3 - A few comments}

The difficulties that participants in this field have had in obtaining experimental results that are clearly reliable should not prevent us from discerning in this bewildering jumble the existence of many suggestive implications. Some of the indications we might draw from them are:

- changes in the position of the mandible influence body posture ${ }^{81}$;

- reciprocally, body posture seems to have an affect on the position of the mandible ${ }^{81}$, with the exception of centric relation and occlusion with maximum inter-cuspation, the localization and reproducibility of both of which are not affected ${ }^{22,98}$;

- habitual mandibular position, or rest position, is tied to cephalic posture ${ }^{103}$;

- head posture seems to influence occlusion $^{82,83}$. It does influence the trajectory of closing, and the position of the initial occlusal contacts $19,24,58,61,90$ On the other hand, a forward inclined head posture does not appear to have any effect on initial occlusal contacts $^{59}$;

- can occlusion affect the way feet support weight? The conclusions of published studies on the point are contradictory. Ferrario et al. ${ }^{29}$ have 
shown that adjustments of the centers of pressure in the feet are not influenced by pain felt in the masticatory system, Class II subdivision malocclusions, or by variations in occlusal positioning. But other studies ${ }^{16,17}$ do assert that the occlusion exerts an influence on the pressures applied through the feet;

- many studies refer to a supposed correlation between malfunction of the masticatory apparatus and an anterior positioning of the head ${ }^{18,50,53,91}$. These correlations should make clinicians consider the advisability of integrating the evaluation and treat ment of postural defects at the same time they are correcting discrepancies in the masticatory system ${ }^{18,45,48,104 \text {; }}$

- but the results reported in another article ${ }^{67}$ do not confirm the hypothesis that body posture provokes or aggravates masticatory discrepancies. Still this work should be evaluated with extreme caution because of the small size of the sample and the large number of postural variables it dealt with;

- the studies that Perinetti carried out using a stabilometric platform did not produce any evidence that there was a correlation between dental occlusion and bodily posture ${ }^{70}$, nor that patients with TMJ problems had perforce alterations in bodily posture $^{71}$;

- patients suffering from internal derangement of the temporomandibular joint do not necessarily hold their heads in an advanced position ${ }^{39}$;

- pain felt in the masticatory apparatus is not associated with cephalic posture ${ }^{100}$;

- a recent systematic review of the literature suggests that the hypothesis that there is a relationship between cervico-cephalic posture and disorders of the masticatory process remains uncertain ${ }^{11}$.

- many articles claim to show that there is a relationship between cervicocephalic posture and cranio-facial morphology. Cervical posture appears to be strongly correlated with structural variations in the sagittal and vertical dimensions of the face ${ }^{12,26,86}$. Positive correlations have also been demonstrated between cervico-cephalic posture and both mandibular and maxillary anterior dento-alveolar height as well as with the inclinations of the upper and lower occlusal planes ${ }^{87}$. Children with Class III skeletal malocclusions present a significantly lower extent of cervical lordosis than those with skeletal Class I or II occlusions ${ }^{26}$. On the other hand, children with Class II skeletal malocclusions have significantly increased cervical lordosis compared with children with Class I or II occlusions ${ }^{26}$, and subjects in Class II keep their heads more forward to a significant extent ${ }^{34}$;

- a study conducted using a posturographic platform showed that subjects in Class II had body posture projected forward and those with Class III malocclusions a bodily posture projected backward ${ }^{68}$;

- a negative correlation exists between cervical lordosis and mandibular length ${ }^{31}$;

- many studies seem to indicate that the afferent impulses of the trigeminal participate in the relationship of occlusion and postural regulation 35,36 . They allege that there is an inter-dependence between the sensory and motor innervations of the trigeminal nerve and the cervical complex ${ }^{20}$;

- there is a significant association between the dominant eye and 
homo-lateral rotation of the head. In patients suffering from discrepancies of the masticatory system there is also a significant association between the side of the cephalic rotation and a contra-lateral deviation of the mandibular incisive midline ${ }^{74}$;

- in a study conducted by P. Gangloff of participants in riflery sports $^{35}$, the stabilization of sight was found to have an effect on postural control through mediation of the dental occlusion;

- Michelotti et al. ${ }^{63}$ studied patients with posterior cross bites using a stabilometer platform and found in two modalities, occlusion at maximum inter-cuspation and a position with teeth held comfortably apart with cotton rolls. They found the cross bites had no effect on the stability of bodily posture. They concluded that there would be no justification for correcting the cross bites if the objective were to prevent or treat a postural problem;

- in addition, another study found that posterior cross bites were not correlated with inequality in leg length of young adolescents ${ }^{64}$;

- an excessive cranio-cervical angulation is associated with lower anterior crowding ${ }^{3,89}$. This conclusion is in accord with a hypothesis about stretching of soft tissues according to which patients with extended craniocervical posture have a blockage of the sagittal growth of their dental arches from the dorsal tension exerted on them;

- does muscular force vary with the occlusion? Maximal biting force is greater when the head is extended than it is when the head is held in a natural position ${ }^{42}$. A splint that places the mandible in a position determined by kinesiological tests would be likely to augment muscular force ${ }^{1,32,33}$ These results contradict those of another published article that avers that there is no correlation between biting force and cephalic posture ${ }^{92}$. Kovero et al. also did not find any significant statistical correlation between maximal biting force and cervical posture ${ }^{49}$;

- the neuromuscular activity of neck and face muscles seems to influence corporal or bodily posture according to many studies ${ }^{25,65,66,84}$, but, according to another one, do not ${ }^{99}$;

- bruxism could be associated with a head posture that is inclined excessively downward and forward ${ }^{101}$;

- a recent systematic review of the literature ${ }^{41}$ surveys 266 publications reporting on a relationship between the masticatory apparatus and disturbances of the spinal column. There is an inter-relation between the masticatory apparatus and head posture according to 216 articles, and an association between pelvic tilting and the oral cavity according to 53 studies. 131 articles conclude that the occlusion affects posture and 171 assert that posture affects occlusion.

These reports from the extensive literature suggest that our mechano-therapies can have an effect on the bodily posture of our patients. But because of the widespread lack of methodological rigor in these investigations, orthodontists should examine the results with prudence and circumspection, especially in view of their tendency to be mutually contradictory. By doing this we can avoid the risk of over-treating our patients by being scrupulously critical when we add postural considerations to our diagnoses ${ }^{41}$. 


\section{4 - THE SPECIAL CASE OF RELATIONSHIP BETWEEN IDIOPATHIC SCOLIOSIS AND OCCLUSION IN ADOLESCENTS}

When a diagnosis of idiopathic scoliosis is made, patients are confronted with the possibility that their spines will continue to develop in a deformed way until the end of the growth period. The best outcome for them would be merely to have to submit to regular check-up examinations about the state of the vertebral column. But some of them will have to endure especially grave orthopedic or surgical treatment. Because of the seriousness of the global effect of the disorder and its esthetic, psychological, and functional repercussions a close study of idiopathic scoliosis helps to answer many questions that arise about the interrelations between posture and occlusion.

\section{4 - 1 - Idiopathic scoliosis and adolescents}

Scoliosis is a three-dimensional structural deformation of the spinal column, with rotation of some vertebrae that causes gibbosities. These deformations cannot be totally corrected, which differentiates them from simple tendencies toward scoliosis. Idiopathic scoliosis makes its appearance before the end of the growth period, unassociated with other pathologies, which also differentiates them from scolioses that are secondary to other problems such as malformations and neurological disorders.

Conventionally, idiopathic scoliosis is called infantile if it is detected before the child is three years old and juvenile if it appears clinically in children from three to ten.
When scoliosis appears in children between the age of ten and the time of skeletal maturation it is said to be adolescent, a category that embraces $80 \%$ of the ensemble of cases of idiopathic scolioses ${ }^{102}$. Affecting more girls than boys, the disorder ${ }^{75}$ is seen in about 2 to $4 \%$ of adolescents between the ages of 10 to 16 .

The etiology of idiopathic scoliosis is probably multi-factorial, with components that are hormonal, connected with growth, with genetics, with metabolic disturbances of collagens and proteoglycanes, with neurological disturbances especially of the proprioceptive and equilibration systems, and with biomechanical factors 21,76 .

With regular clinical and radiological examinations the progress of the malady can be observed. According to Lonstein and Carlson ${ }^{57}$, the topography of the individual case of scoliosis, the patient's age at the time it was discerned, the initial degree of angulation, the results of the Risser test, and, for girls, the date of the onset of menstruation, can all be evaluated as factors in the "prediction of curvature progression in untreated idiopathic scoliosis during growth." Treatment of evolving idiopathic scoliosis is usually conservative at first having the objective improving the appearance and the functioning of the spinal column and preventing any aggravation of the curvatures that have already occurred. Some patients are asked to wear braces that are adjusted to various degrees of correction. When the malady progresses unfavorably and the deformation becomes more serious, surgical treatment may be indicated. 
But, throughout, careful observation of the patients and their families is of primordial importance because the necessary procedures can be long, tedious, and extremely constraining. The primary goal with all patients is to limit the development of the scoliosis so that it does not become a serious impediment to a normal, active life when patients become adults.

\section{4 - 2 - Adolescents with idiopathic scoliosis and orthodontic treatment}

How should orthodontists deal with patients who suffer from idiopathic scoliosis? Does the malady exert a pernicious effect on the patient's occlusion? Will orthodontic treatment ameliorate or aggravate the patient's overall health? These are the principal questions that must be answered when patients with scoliosis seek an orthodontic consultation.

Cases of idiopathic scoliosis often develop in unpredictable ways during growth periods. Not infrequently, the malady may become more grave or, in other cases, stabilize ${ }^{38}$ during the time a patient is undergoing orthodontic treatment and the orthodontist's mechano-therapy may be blamed or given credit. This, of course would affirm without a shred of proof that an association between two phenomena establishes a cause and effect relationship between them.

This calls to mind a parallel between another debate that caused a considerable stir in orthodontic circles during the 1980s when orthodontic treatment was alleged to have caused some patients temperomandibular disorders or so-called TMJ problems. During the epidemic of this unfortunate witch hunt some patients actually obtained substantial financial awards $^{73}$ for alleged malpractice. Fortunately a series of subsequent clinical studies ${ }^{62}$ was able to prove that dento-facial orthopedic treatment did not increase the risk of a patient's developing tempero-mandibular maladies.

We have derived the answer to the series of questions we posed by means of a virtual dialogue between members of diverse health disciplines in an attempt to restore some unity to the evaluation of patients whose examinations are too often fragmented into studies of separate organs to fit the vision of a host of medical specialties and by a careful study of the literature.

\section{4 - 3 - The occlusion of adolescents with idiopathic scoliosis: what does the published data tell us?}

Many studies have been carried out to try to determine if a scoliotic deformation can be associated not only with adaptive asymmetries of postural control but also with a particular type dento-skeletal formation.

\section{4 - 3 - 1 - Does treatment of scoliosis tend to affect a patient's dento-facial equilibrium?}

During the decades of the 1960 and 70s many articles were published about the deleterious effects on facial growth that orthopedic treatment of scoliosis with a Milwaukee brace could cause.

In a 1966 article R. G. Alexander ${ }^{2}$ presented evidence that there was a significant reduction of facial height, 
an elevation of the palatal plane, a flattening of the palatal vault, a tilting, lower and forward, of the mandibular symphasis, intruding of molars, and labial tilting of maxillary and mandibular incisors during treatment of scoliosis with the Milwaukee brace.

Other authorities subsequently suggested that patients wear a variety of appliances, such as the monobloc, to counteract the adverse oro-facial effects of the Milwaukee brace $^{77}$.

Because of these studies the Milwaukee brace was then modified so that it would be less likely to provoke unwelcome iatrogenic side effects $^{54,60}$. More recently Huggare et al. ${ }^{44}$ described the less substantial side effects of orthopedic treatment for scoliotic patients undertaken with a Boston brace. These patients were distinguished from a control group by an accentuation of the cranio-cervical angle, a rotation of the orbital plane, maxillary, and mandibular planes, a displacement of the mid-line of the mandibular arch, and a flattening of the posterior arch of the first cervical vertebra associated with a lengthening of the dent de l'axis.

\section{4 - 3 - 2 - Correlation between idiopathic scoliosis and dento-skeletal characteristics}

Pecina $M$ et al. have classified orthodontic anomalies into two categories, hereditary and acquired. They show that in scoliotic patients ${ }^{69}$ there is a higher rate of occurrence of hereditary orthodontic anomalies like hypodontia, which is 10 times more frequent and prognathic mandibles. On the other hand, these authors did not find a higher incidence of acquired orthodontic anomalies in scoliosis patients. They suggest that early detection of hereditary orthodontic discrepancies would allow health care givers to identify a group of infants with a high risk of later developing scoliosis.

Lippold et al. found a statistically significant correlation between Class II malocclusion and scoliosis ${ }^{55}$.

They recommend that all preschool children with Class II malocclusions, no matter how slight, should be carefully watched for possible development of spinal abnormalities (fig. 3 a to $\mathrm{c}$ ).

The authors of another article ${ }^{46}$ conclude that there is a correlation between skeletal anomalies of Class I, II, or III, hypo or hyper-divergent, and scoliosis.

The study that Ben-Bassat et al. ${ }^{13}$ published showed patients with scoliosis had more than an average amount of asymmetries in the sagittal and transverse dimensions. Other investigators have observed that patients with scoliosis have prevalence statistically greater than average of Class II subdivision malocclusions, lower incisal mid-line deviations, and, especially, mandibular deviations, as well as anterior and posterior cross bites. On the other hand, no significant correlation has been established between the side to which the spine is deformed and the side of the posterior cross bite or the side to which the mandibular midline is deviated. Some authors do draw our attention to the possibility that the asymmetries of scoliosis and of malocclusion share a common etiology. Should this be true the global correction of a malocclusion, and its retention, could be more uncertain. They advise practitioners 

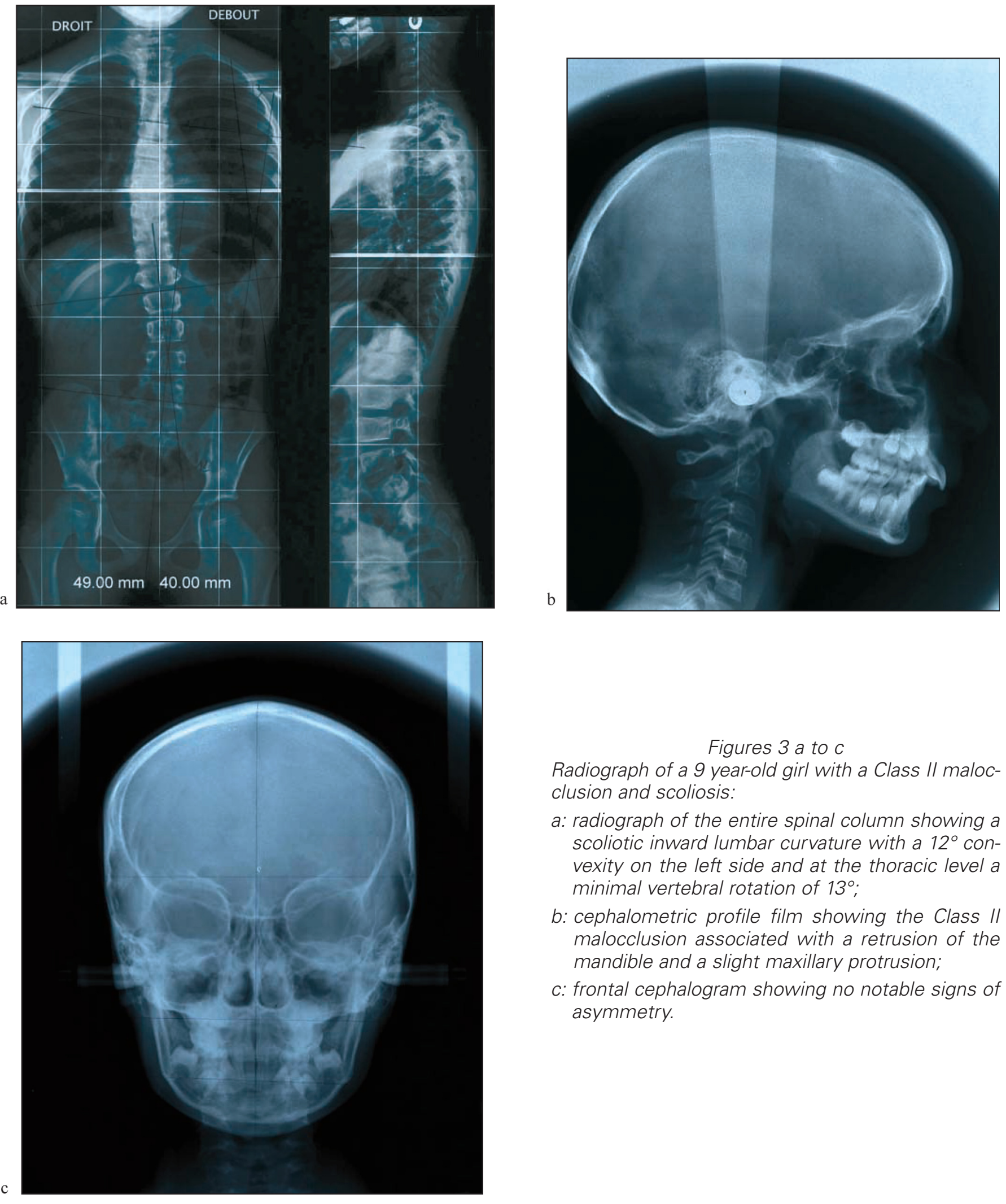

Figures 3 a to $c$

Radiograph of a 9 year-old girl with a Class II malocclusion and scoliosis:

a: radiograph of the entire spinal column showing a scoliotic inward lumbar curvature with a $12^{\circ}$ convexity on the left side and at the thoracic level a minimal vertebral rotation of $13^{\circ}$;

b: cephalometric profile film showing the Class II malocclusion associated with a retrusion of the mandible and a slight maxillary protrusion;

c: frontal cephalogram showing no notable signs of asymmetry. 
examining patients to look for under-lying orthopedic problems when they have made a diagnosis ${ }^{14}$ of early signs of dento-facial asymmetry.

Still other workers have studied the relationship between dental occlusion and posture in animals. Festa et al. ${ }^{30}$ studied the effects in rats of uni-laterally opening their bites by adding composite to posterior teeth. After one week a radiological examination showed a marked deviation of the animals' vertebral columns. When researchers opened the bite similarly on the other side the spinal column straightened up. More recently D'Attilio et al. ${ }^{27}$ also induced scoliotic curvature in the spinal columns of rats in a week's time by uni-laterally raising the occlusion. When the researchers restored occlusal harmony by elevating the contralateral side of the occlusion, vertebral alignment of $83 \%$ of the rats in the study returned to the original condition. This seems to make clear that spinal column alignment in rats can be influenced by dental occlusion.

So clinicians are faced with the question of determining to what extent experimental observations made in animal studies can be applied to daily practice. Even if the results of animal studies should not be extrapolated to apply to people but tested on humans first before they are accepted, their conclusions should, at the very least induce practitioners to conduct any mechanical adjustment that could lead to occlusal imbalance with extreme care.

\section{4 - 4 - Clinical implications}

The strong prevalence of associations between scoliosis and craniofacial anomalies argues persuasively for the related disciplines of general orthopedics and dento-facial orthopedics to work cooperatively in early diagnosis of patients and in increasing the effectiveness of the treatment of those patients.

In this way orthodontists could contribute to the orthopedist's beginning early treatment of spinal cord deformities by suggesting an orthopedic consultation when orthodontic examinations have uncovered certain indicative dento-skeletal characteristics such as Class II malocclusion or dento-facial asymmetry.

It should be emphasized that when orthodontists do not include every facet of their patients' health status in their examinations they may risk missing important diagnostic elements. When they are confronted with a polymorphous symptomology, they must endeavor to assess all of its dimensions including postural in order to avoid parceling treatment into isolated and ineffective components.

Certainly the achievement of a harmonious and esthetic smile for our patients (fig. 4 and fig. 5 a and b) remains one of the objectives of our treatment but the therapeutic perspectives of our specialty go far beyond that. In addition to placing our patients' faces, jaws, and dental arches in better esthetic and functional equilibrium (fig. 6 a and b, and fig. 7 a to d) we strive, especially, to re-establish optimal nasal breathing ${ }^{97}$, and also to place the soft tissues of the face and the craniocervical complex in the best possible postural position. The most exacting integration of postural considerations in our daily practices should be as effortless as was that of the uncovering and treatment of other 


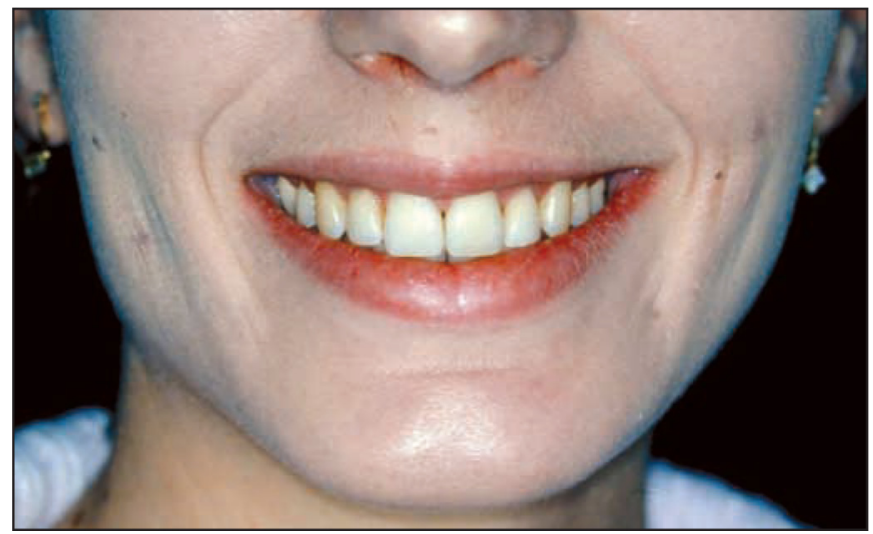

Figure 4

Esthetic harmony of the smile was one of the objectives of treatment in the dentofacial orthopedic treatment of this young adult.

malfunctionings of masticatory apparatus. We already use every day many therapeutic tools of the postural approach, such as orthopedic appliances and occlusal splints, elastic positioners, and myo-functional therapy. Adding postural evaluations to the list of our habitual auxiliary examination procedures such as mounting models on articulators, making occlusal, axial, electroymyographic, and radiological analyses would simply make our diagnostic procedures more complete.

But it is not only desirable but essential that we integrate a postural approach into the practice of dento-facial orthopedics by also including it as a component of education of patients ${ }^{10}$. In the same way that we have already incorporated a concern for the way they breathe into our instructions to and supervision of patients, we can present our didactic sessions on posture to patients by basing them on sound physiological principles so as to capture their interest and cooperation as well as the participation of their families. When orthodontists incorporate this postural strategy into their daily office procedures they will begin to have the great joy of receiving the thanks of patients
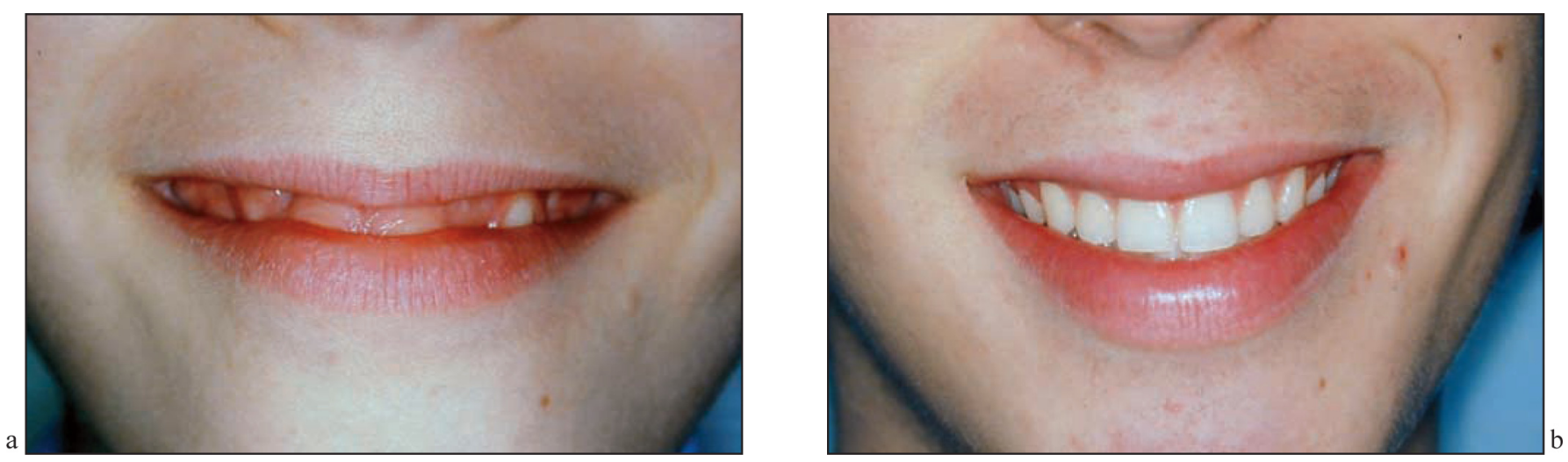

Figures $5 a$ and $b$

Non-surgical correction of a smile showing too much gingiva for this ten year-old boy. 

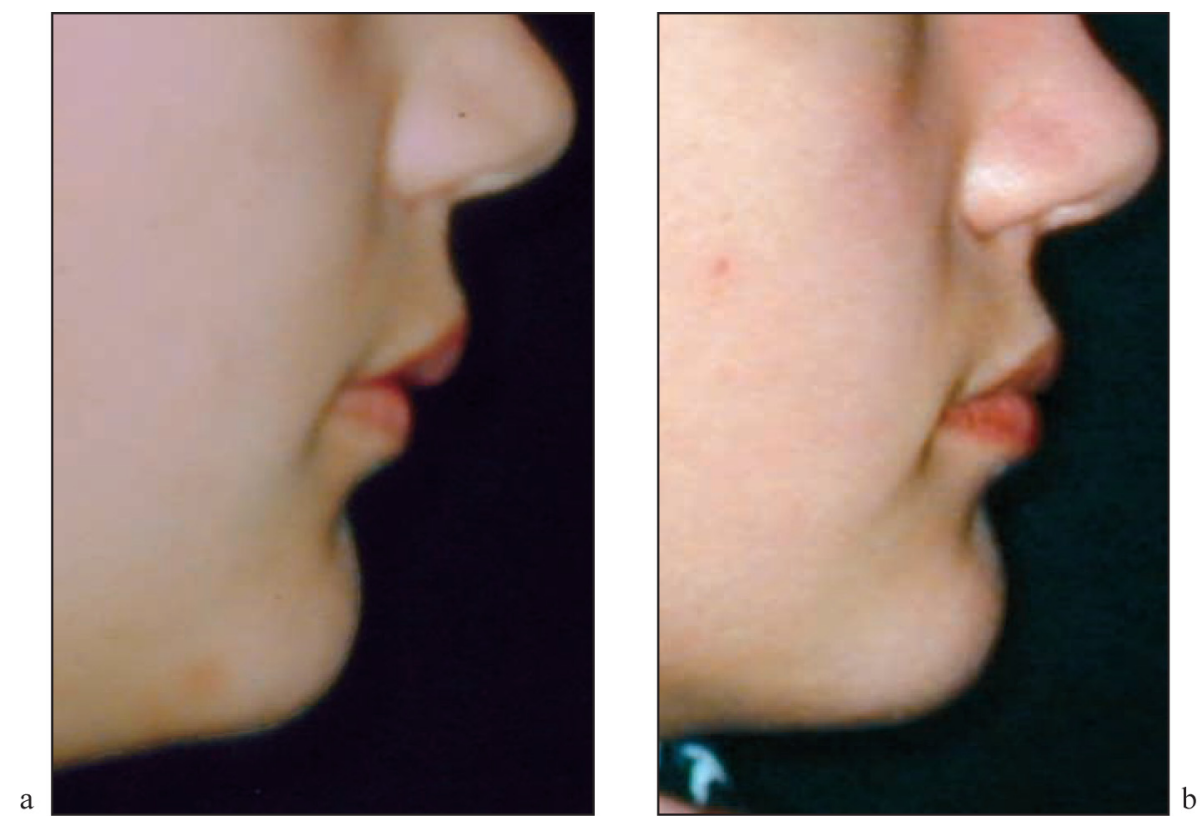

Figures $6 a$ and $b$ Right profile photographs:

a: before treatment;

b: after treatment.

and their families not only for having improved the esthetics of their patients' smiles but also for the extraordinary contribution to their well being by having improved the quality of their lives.

This attitude of making patient participants in treatment not simple recipients of it, sometimes thought of as patient education but, in reality, of far wider scope than that, raises patients to the status of equal partners in the therapeutic enterprise ${ }^{10}$. This demarche can be broken down into three clinical entities that have routinely been described as ${ }^{28}$ : health;

- information about the patient's

- information about the patient's malady;

- education about the patient's therapy.

As specialists in caring for the health of children it is highly desirable that orthodontists disseminate all three of these types of information.
Because of the limited amount of space available for this article, we haven't been able to discuss the therapeutic education of children in detail. But by at least formulating its three principal aspects we wish to emphasize quite explicitly that education of patients is integral part of our treatment. We also strongly believe that instructing them about how to participate in their therapy, notably in myo-functional training, especially of breathing, is only one part (fig. 8) of the pedagogical relationship between orthodontists and patients that should be a part of every visit. Centered on the patient, these sessions should be adapted to their age and the psychosocial context in which they live and should encompass all the educational aspects of preventive and curative treatment. The goal of this enterprise is to help patients, with the assistance of their families, to acquire the full competence for attaining, among other goals, the capacity for good nasal breathing. 

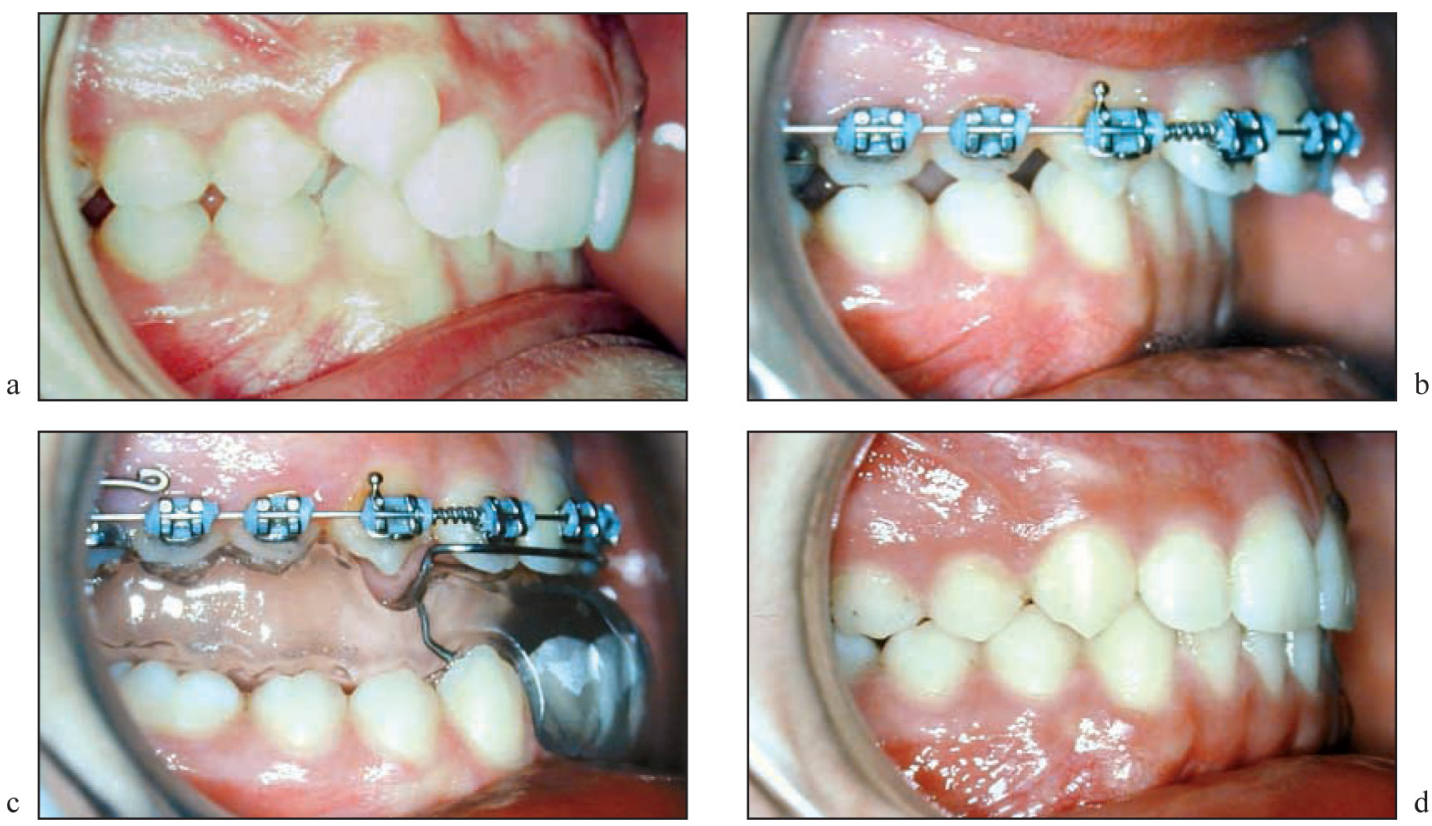

Figures 7 a to $d$

Right intra-oral photographs of the same patient:

a: before treatment;

b: after the maxilla has been harmonized with the mandible;

c: orthopedic correction of the Class II malocclusion with a functional acrylic splint and orthopedic treatment5,

d: after treatment.

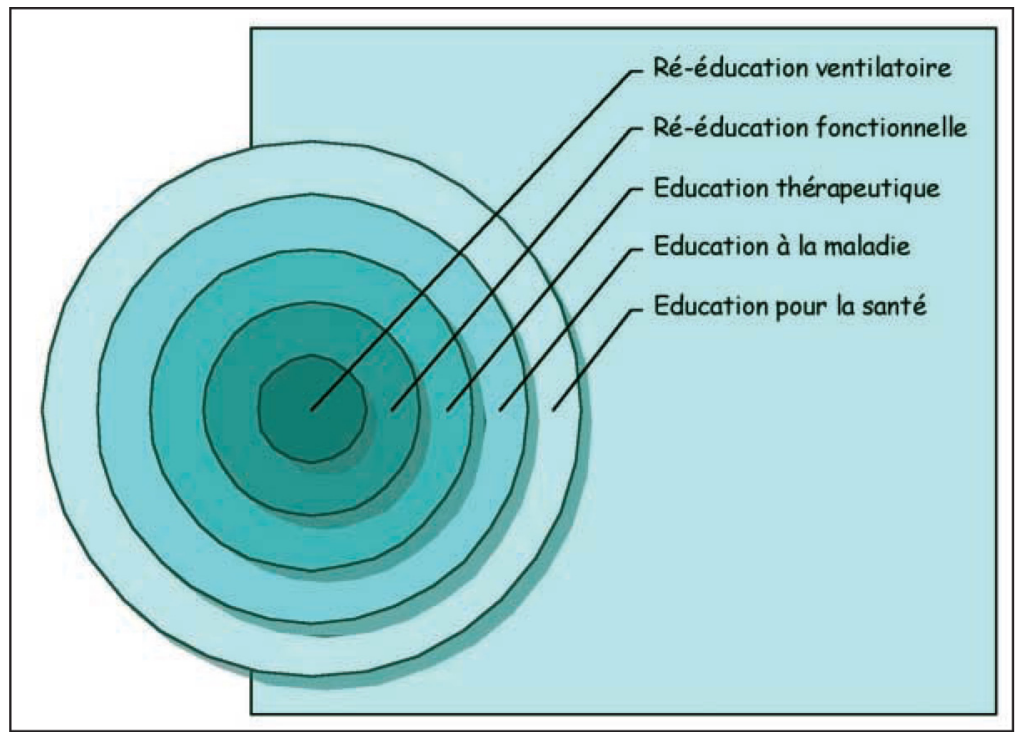

Figure 8

Instructing the patient in the principles of dentofacial orthopedics ${ }^{10}$. 


\section{5 - CONCLUSIONS}

In presenting the correlation between dental occlusion and posture published data tends to lend comfortable support for the convictions and clinical impressions we have already formed. The physiological continuum tying occlusion to posture does not appear to be a univocal and linear relationship but instead a complex ensemble made up of numerous contributing factors. We need to realize that our patients can be considered entities made of tightly connected psychic and somatic components whose complexity provoked Rudolph Slavicek ${ }^{85}$ to propose a cybernetic concept of the mechanism of inter-reaction of the components of the masticatory system (fig. 9). Instead of calling it an apparatus, which designates an ensemble of organs working together in the same function, he prefers the term organism because the masticatory organism fulfills numerous functions. In fact, this ensemble of organs working in a coordinated and hierarchal manner does more than just execute the activities of mastication and deglutition. It also participates in speech, breathing, maintenance of posture, esthetic appearance, and control of emotions and stress. The Central Nervous System regulates these functions not only by neurological somatic control but also by conscious and unconscious psychic interference. R. Slavicek makes a special point of stressing that the methods modern humans use to deal with the pressures and assaults they suffer in daily life often focus on the masticatory organism as an exhaust valve to relieve unconscious psychic charges or stress.

We must ask ourselves, then, is the frequent association between posture and facial deformities the result of pure coincidence or is it evidence of a real pathological development whose meaning is just beginning to be clarified? With what

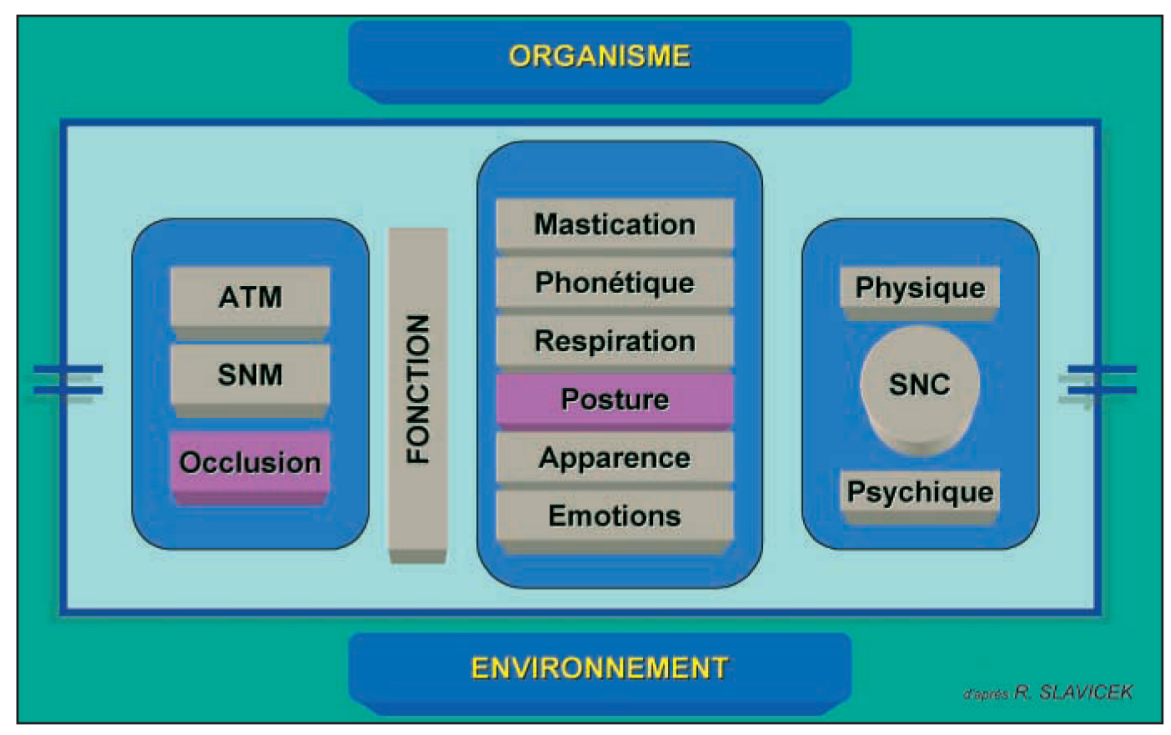

Figure 9

After Slavicek ${ }^{85}$. Cybernetic concept of the mechanisms of the system of inter-reactions of the masticatory organism. 
therapeutic techniques should we deal with these problems? Posing these questions and attempting to answer them is the indispensable pre-requisite for orthodontists to incorporate an evaluation of problems with posture and a consideration of their eventual repercussions in our dento-facial orthopedic treatment. And to find answers we need to undertake basic and clinical research projects that could eventually establish the validity of a cause and effect relationship between dental occlusion and posture without which there can be no sure indications for the directions orthodontic therapy for postural defects should take.

In the final analysis, by including postural considerations in our diagnoses, we shall be moving along the road that leads to a total corporal analysis of our patients. This approach will reinforce our communications with other health care deliverers and encourage us to treat our patients in a multi-disciplinary collaboration with our colleagues in other specialties. We are convinced that such a joint enterprise will be a key element in our common raison d'etre: caring for the over-all health and well-being of our patients.

\section{REFERENCES}

1. Abdallah EF, Mehta NR, Forgione AG, Clark RE. Affecting upper extremity strength by changing maxillo-mandibular vertical dimension in deep bite subjects. Cranio 2004;22:268-75.

2. Alexander RG. The effects on tooth position and maxillofacial vertical growth during treatment of scoliosis with the Milwaukee brace. Am J Orthod 1966;52:16189.

3. AlKofide EA, AlNamankani E. The association between posture of the head and malocclusion in Saudi subjects. Cranio 2007;25:98-105.

4. Amat $P$ et al. Evaluation with World Health Organization criterias of TMD and myofascial disorders. CED-IADR 35 $5^{\text {th }}$ Annual Meeting September 23-25, 1999 Montpellier, France. J Dent Res 2001;80:1194-1255.

5. Amat P. Contribution of a functional and orthopaedic splint to the treatment of Class II malocclusions. $103^{\text {rd }}$ Annual Session of the American Association of Orthodontists; 2003 May 2-6; Honolulu, Hawaii.

6. Amat P. Apport d'une gouttière fonctionnelle et orthopédique au traitement des malocclusions de classe II. Orthod Fr 2003;74:71-81.

7. Amat P. Functional orthopaedic treatment in the growing child and temporomandibular disorders: a review of literature. Closed meeting of the European Academy of Craniomandibular Disorders, Bordeaux, France, September 2003.

8. Amat P. Orthopédie dento-faciale fondée sur les faits : marotte d'universitaire ou indispensable outil clinique quotidien? Rev Orthop Dento Faciale 2006;40:421-51.

9. Amat P. What would you choose: evidence-based treatment or an exciting, risky alternative? Am J Orthod Dentofacial Orthop 2007;132:724-5.

10. Amat P. Stress et orthodontie. XXV Journées Internationales du Collège National d'Occlusodontologie. Stress, douleurs et dysfonctionnements. 13 et 14 mars 2008 Brest. 
11. Armijo Olivo S, Bravo J, Magee DJ, Thie NMR, Major PW, Flores-Mir C. The association between head and cervical posture and temporomandibular disorders: a systematic review. J Orofac Pain 2006;20:9-23.

12. Bacon W, Turlot JC, Blaise M. La reproductibilité de la posture naturelle de la tête et son implication dans l'organisation de l'architecture cranio-faciale. Rev Orthop Dento-Faciale 1989;23:277-86.

13. Ben-Bassat $Y$, Yitschaky M, Kaplan L, Brin I. Occlusal patterns in patients with idiopathic scoliosis. Am J Orthod Dentofacial Orthop 2006;130:629-33.

14. Bodin CG, Duguet $V$, Hervé F. Diagnostic des latérognathies mandibulares. Intérêt de la butée occlusale d'Abjean. Rev Orthop Dento Faciale 1992;26:81-6.

15. Bounoure GM, Frindel F. Le miroir aux alouettes. Rev Orthop Dento Faciale 1981;15:211-3.

16. Bracco P, Deregibus A, Piscetta R, Ferrario G. Observations on the correlation between posture and jaw position: a pilot study. Cranio 1998;16:252-8.

17. Bracco P, Deregibus A, Piscetta R. Effects of different jaw relations on postural stability in human subjects. Neurosci Lett 2004;356:228-30.

18. Braun BL. Postural differences between asymptomatic men and women and craniofacial pain patients. Arch Phys Med Rehabil 1991;72:653-6.

19. Brenman HS., Amsterdam M. Postural effects on occlusion. Dental Progress 1963;4:43-7.

20. Browne PA, Clark GT, KubokiT, Adachi NY. Concurrent cervical and craniofacial pain. A review of empiric and basic science evidence. Oral Surg Oral Med Oral Pathol Oral Radiol Endod 1998;86:633-40.

21. Burwell RG. Aetiology of idiopathic scoliosis: current concepts. Pediatr Rehabil 2004;6:137-70.

22. Campos AA, Nathanson D, Rose L. Reproducibility and condylar position of a physiologic maxillomandibular centric relation in upright and supine body position. J Prosthet Dent 1996;76:282-7.

23. Commission de terminologie. Dictionnaire d'orthognathodontie. Paris, SFODF, 2007.

24. Chapman RJ et al. Occlusal contact variation with changes in head position. Int J Prosthodont 1991;4:377-81.

25. De Mayo T et al. Breathing type and body position effects on sternocleidomastoid and suprahyoid EMG activity. J Oral Rehabil 2005;32:487-94.

26. D'Attilio M, Caputi S, Epifania E, Festa F, Tecco S. Evaluation of cervical posture of children in skeletal Class I, II, and III. Cranio 2005;23:219-28.

27. D'Attilio M, Filippi MR, Femminella B, Festa F, Tecco S. The influence of an experimentally-induced malocclusion on vertebral alignment in rats: a controlled pilot study. Cranio 2005;23:119-29.

28. Deccache A. Quelles pratiques et compétences en éducation du patient? Recommandations de I'O.M.S. La Santé de I'homme 1999;341:12-4.

29. Ferrario VF, Sforza C, Schmitz JH, Taroni A. Occlusion and center of foot pressure variation: is there a relationship? J Prosthet Dent 1996;76:302-8.

30. Festa F, D'Attilio M, Vecchiet F. Effects of horizontal oscillation of the mandible on the spinal column of the rat in vivo using radiographic monitoring. Ortogntodonzia Ital 1997;6:539-50.

31. Festa $\mathrm{F}$ et al. Relationship between cervical lordosis and facial morphology in Caucasian women with a skeletal Class II malocclusion: a cross-sectional study. Cranio 2003;21:121-9. 
32. Forgione AG, Mehta NR, Westcott WL. Strength and bite. Part 1: An analytical review. Cranio 1991;9:305-15.

33. Forgione AG, Mehta NR, McQuade CF, Westcott WL. Strength and bite. Part 2: Testing isometric strength using a MORA set to a functional criterion. Cranio 1992;10:13-20.

34. Gadotti IC, Bérzin F, Biasotto-Gonzalez D. Preliminary rapport on head posture and muscle activity in subjects with Class I and II. J Oral Rehabil 2005;32:794-9.

35. Gangloff P, Louis JP, Perrin PP. Dental occlusion modifies gaze and posture stabilization in human subjects. Neurosci Lett 2000;293:203-6.

36. Gangloff P, Perrin PP. Unilateral trigeminal anaesthesia modifies postural control in human subjects. Neurosci Lett 2002;330:179-82.

37. Glenny AM, Harrison JE. How to interpret the orthodontic literature. J Orthod 2003;30:159-64.

38. Guillaumat M. Scoliose idiopathique de l'enfant et de l'adulte jeune. Rev Rhum 2004;71:145-59.

39. Hackney J, Bade D, Clawson A. Relationship between forward head posture and diagnosed internal derangement of the temporomandibular joint. J Orofac Pain 1993;7:386-90.

40. Halm EA, Tuhrim S, Wang JJ, Rojas M, Hannan EL, Chassin MR. Has evidence changed practice? Appropriateness of carotid endarterectomy after the clinical trials. Neurology 2007;68:187-94.

41. Hanke BA, Motschall E, Türp JC. Association between orthopedic and dental findings: what level of evidence is available? J Orofac Orthop 2007;68:91-107.

42. Hellsing $E$, Hagberg $C$. Changes in maximum bite force related to extension of the head. Eur J Orthod 1990;12:148-53.

43. Huang GJ. Fasten your seat belts for the bumpy ride to evidence-based practice. Am J Orthod Dentofacial Orthop 2005;127:4-5.

44. Huggare J, Pirttiniemi P, Serlo W. Head posture and dentofacial morphology in subjects treated for scoliosis. Proc Finn Dent Soc 1991;87:151-8.

45. Huggare JA, Raustia AM. Head posture and cervicovertebral and craniofacial morphology in patients with craniomandibular dysfunction. Cranio 1992;10:173-7.

46. Ikemitsu $H$, Zeze R, Yuasa $K$, Izumi $K$. The relationship between jaw deformity and scoliosis. Oral Radiol 2006;22:14-7.

47. Kemoun G. La posturographie peut-elle participer a l'étude des désordres thymocognitifs? Lettre Méd Phys Réadapt 2007;23:153-7.

48. Komiyama $\mathrm{O}$ et al. Posture correction as part of behavioural therapy in treatment of myofascial pain with limited opening. J Oral Rehabil 1999;26:428-35.

49. Kovero $O$ et al. Maximal bite force and its associations with spinal posture and craniofacial morphology in young adults. Acta Odontol Scand 2002;60:365-9.

50. Kritsineli M, Shim YS. Malocclusion, body posture, and temporomandibular disorder in children with primary and mixed dentition. J Clin Pediatr Dent 1992;16:86-93.

51. Krumholz HM, Radford MJ, Wang Y, Chen J, Helat A, Marciniak TA. National use and effectiveness of beta-blockers for the treatment of elderly patients after acute myocardial infarction. National Cooperative Cardiovascular Project. JAMA 1998;280:623-9.

52. Laplanche O. Occlusion et posture: analyse de la littérature. $17^{\text {es }}$ Journées Internationales du CNO 2000, 24-25 mars, Nice.

53. Lee WY, Okeson JP, Lindroth J. The relationship between forward head posture and temporomandibular disorders. J Orofac Pain 1995;9:161-7. 
54. Links Persky SL, Johnston LE. An evaluation of dentofacial changes accompanying scoliosis therapy with a modified Milwaukee brace. Am J Orthod 1974;65:364-71.

55. Lippold C, van den Bos L, Hohoff A, Danesh G, Ehmer U. Interdisciplinary study of orthopedic and orthodontic findings in pre-school infants. J Orofac Orthop 2003;64:330-40.

56. Li Wan Po A. Dictionary of Evidence Based Medecine. Oxon: Radcliffe Medical Press, 1998.

57. Lonstein JE, Carlson JM. The prediction of curve progression in untreated idiopathic scoliosis during growth. J Bone Joint Surg 1984;66:1061-71.

58. Makofsky HW, Sexton TR, Diamond DZ et al. The effect of head posture on muscle contact position using the T-scan system of occlusal analysis. Cranio 1991;9:316-21.

59. Makofsky HW. The influence of forward head posture on dental occlusion. Cranio 2000 Jan;18:30-9.

60. Mathis R, Bacon W, Siffert B. Facial growth of children wearing a modified Milwaukee brace. Orthod Fr 1982;53:697-704.

61. McLean LF, Brenman HS, Friedman MGF. Effects of changing body position on dental occlusion. J Dent Res 1973;52:1041-5.

62. McNamara J, Seligman DA, Okeson JP. Occlusion, orthodontic treatment, and temporomandibular disorders: a review. J Orofacial Pain 1995;9:73-90.

63. Michelotti A et al. Postural stability and unilateral posterior crossbite: is there a relationship? Neurosci Lett 2006;392:140-4.

64. Michelotti $A$ et al. Is unilateral posterior crossbite associated with leg length inequality? Eur J Orthod 2007;29:622-6.

65. Miralles $\mathrm{R}$ et al. Body position effects on EMG activity of sternocleidomastoid and masseter muscles in healthy subjects. Cranio 1998;16:90-9.

66. Miralles $\mathrm{R}$ et al. Body position and jaw posture effects on supra- and infrahyoid electromyographic activity in humans. Cranio 2006;24:98-103.

67. Munhoz WC, Marques AP, de Siqueira JT. Evaluation of body posture in individuals with internal temporomandibular joint derangement. Cranio 2005;23:269-77.

68. Nobili A, Adversi R. Relationship between posture and occlusion: a clinical and experimental investigation. Cranio 1996;14:274-85.

69. Pecina M, Lulic-Dukic O, Pecina-Hrncevic A. Hereditary orthodontic anomalies and idiopathic scoliosis. Int Orthop 1991;15:57-9.

70. Perinetti G. Dental occlusion and body posture: no detectable correlation. Gait Posture 2006;24:165-8.

71. Perinetti G. Temporomandibular disorders do not correlate with detectable alterations in body posture. J Contemp Dent Pract 2007;8:60-7.

72. Pionchon P, Duminil G. Occlusion et posture: les questions qui se posent. $17^{\mathrm{es}}$ Journées Internationales du CNO 2000, $24-25$ mars, Nice.

73. Pollack B. Cases of note: Michigan jury awards $\$ 850,000$ in ortho case: A tempest in a teapot. Am J Orthod Dentofacial Orthop 1988;94:358-9.

74. Pradham NS, White GE, Mehta N, Forgione A. Mandibular deviations in TMD and non-TMD groups related to eye dominance and head posture. J Clin Pediatr Dent 2001;25:147-55.

75. Roach JW. Adolescent idiopathic scoliosis. Orthop Clin North Am 1999;30:353-65.

76. Robin GC. The aetiology of idiopathic scoliosis. A review of a century of research. Boca Raton, Fla: Freund Publishing House, 1990. 
77. Roth NM. The modified monobloc appliance in scoliosis treatment. Am J Orthod 1969;55:506-9.

78. Sackett D. Rules of evidence and clinical recommendations. Can J Cardiol 1993;9:487-9.

79. Sackett DL, Rosenberg WM, Gray JA, Haynes RB, Richardson WS. Evidence based medicine: what it is and what it isn't. BMJ 1996;312:71-2.

80. Sackett DL, Strauss SE, Richardson WS, Rosenberg W, Haynes RB. Evidence-based medicine: how to practice and teach EBM. London: Churchill-Livingstone, 2000.

81. Sakaguchi $\mathrm{K}$ et al. Examination of the relationship between mandibular position and body posture. Cranio 2007;25:237-49.

82. Salonen MA, Raustia AM, Huggare J. Head and cervical spine postures in complete denture wearers. Cranio 1993;11:30-3.

83. Santander $\mathrm{H}$ et al. Influence of stabilisation occlusal splint on craniocervical relationships. Part II: electromyographic analysis. Cranio 1994;12:227-33.

84. Santander $\mathrm{H}$ et al. Effects of head and neck inclination on bilateral sternocleidomastoid EMG activity in healthy subjects and in patients with myogenic craniocervical-mandibular dysfunction. Cranio 2000;18:181-91.

85. Slavicek R. Approche cybernétique des structures et fonctions de l'appareil manducateur. Communication aux IX Journées Internationales du CNO, in Actes des journées. 13, 14 et 15 mars 1992, Lyon.

86. Solow B, Tallgren A. Head posture and craniofacial morphology. Am J Phys Anthropol 1976;44:417-36.

87. Solow B, Tallgren A. Dentoalveolar morphology in relation to craniocervical posture. Angle Orthod 1977; 47:157-64.

88. Solow B, Siersbaek-Nielsen S Cervical and craniocervical posture as predictors of craniofacial growth. Am J Orthod Dentofacial Orthop 1992;101:449-58.

89. Solow B, Sonnesen L. Head posture and malocclusions. Eur J Orthod 1998;20:685-93.

90. Solow B, Sandham A. Cranio-cervical posture: a factor in the development and function of the dentofacial structures. Eur J Orthod 2002;24:447-56.

91. Sonnesen L, Bakke M, Solow B. Temporomandibular disorders in relation to craniofacial dimensions, head posture and bite force in children selected for orthodontic treatment. Eur J Orthod 2001;23:179-92.

92. Sonnesen L, Bakke M. Molar bite force in relation to occlusion, craniofacial dimensions, and head posture in pre-orthodontic children. Eur J Orthod 2005;27:58-63.

93. Southard TE, Southard KA, Tolley EA. Variation of approximal tooth contact tightness with postural change. J Dent Res 1990;69:1776-9.

94. Sutherland SE. An introduction to systematic reviews. J Evid Base Dent Pract 2004;4:47-51.

95. Talmant J, Deniaud J, Nivet M-H. Définition de la «ventilation nasale optimale». In : La dimension verticale. 1 - Ventilation nasale et dimension verticale : bases morphologiques et physiologiques. Orthod Fr 2003;74:201-25.

96. Talmant J, Deniaud J, Nivet M-H. Mécanismes posturaux. In: La dimension verticale. 1 - Ventilation nasale et dimension verticale: bases morphologiques et physiologiques. Orthod Fr 2003;74:227-83.

97. Talmant J, Deniaud J. Optimal nasal ventilation: a physiological definition. Arch Pediatr 2008;15:873-4.

98. Tripodakis AP, Smulow JB, Mehta NR, Clark RE. Clinical study of location and reproducibility of three mandibular positions in relation to body posture and muscle function. J Prosthet Dent 1995;73:190-8. 
99. Valenzuela $S$ et al. Does head posture have a significant effect on the hyoid bone position and sternocleidomastoid electromyographic activity in young adults? Cranio 2005;23:204-11.

100. Visscher CM, De Boer W, Lobbezoo F, Habets LL, Naeije M. Is there a relationship between head posture and craniomandibular pain? J Oral Rehabil 2002;29:1030-6.

101. Vélez AL et al. Head posture and dental wear evaluation of bruxist children with primary teeth. J Oral Rehabil 2007;34:663-70.

102. Weinstein SL, Buckwalter JA, editors. Turek's orthopedics, principles and their application. $5^{\text {th }}$ ed Philadelphia: JB Lippincott, 1994.

103. Woda A, Pionchon P, Palla S. Regulation of mandibular postures: mechanisms and clinical implications. Crit Rev Oral Biol Med 2001;12:166-78.

104. Wright EF, Domenech MA, Fischer JR Jr. Usefulness of posture training for patients with temporomandibular disorders. J Am Dent Assoc 2000;131:202-10. 